Perinchery Narayan

\section{Benign Prostatic Hyperplasia}

New York, Churchill Livingstone 2000

402 pp., GBP 99.00

ISBN 0-4430-5637-4

At first glance, this book on benign prostatic hyperplasia is impressive due to its high-quality figures. The glossy paper underscores the excellent impression. In seven sections, an up-to-date information on benign prostatic hyperplasia is presented by renown experts in this field. Holtgrewe covers the costs, Barry and O'Leary provide a fundamental chapter on health-related quality of life, and Roehrborn writes about the Agency for Health Care Policy and guidelines in Clinical Research. If it comes to treatment you find an answer to virtually every question concerning the variety of management possibilities to choose from.

Concerning $\alpha_{1}$-blockers, too much emphasis is given to tamsulosine as opposed to other $\alpha_{1}$-blocking agents. In this chapter, some of the weaknesses of the commentary ought to be mentioned. They are mostly reiterative of what has been covered already in the text. The chapter on laser treatment is an excellent update of what has been achieved. One wonders, however, why none of the laser treatments did gain great popularity, at least in Germany. The same holds true if other minimally invasive treatments like transurethral needle abla- tion are described. Again, although feasible, the popularity lacks behind, there is apparently low invasiveness; one reason might be (figure 21.9), for example, concerning transurethral needle ablation during the static and dynamic voiding phase, that residual tissue at the apex remains obstructive after application of this interstitial ablative technique. Following a conventional transurethral resection of the prostate apical residual tissue is a common cause for a necessary reintervention. Other minimally invasive treatments like transurethral thermotherapy or stents never gained great acceptance in Germany. If you ever had to remove an obstructed wall stent from the prostate in an apparently inoperable patient you know why. The chapter on conventional transurethral resection of the prostate from John Blandy gives many helpful technical hints which will serve even the experienced surgeon well. The final chapter covers future trends, for example the Rotoresect, which may play a role in therapy in the future.

In essence, this book lives from its excellent illustrations and an up-to-date account of the results. However, the array of treatment options should be restricted depending on the disease to avoid the administration of the whole therapeutic cascade. Most patients do not wish to start with one or two sessions of transurethral thermotherapy and wind up with transurethral resection of the prostate. The high quality of the book and complete coverage of all aspects of benign prostatic hyperplasia will finally convince the urologist to include this book into his library.

\section{KARGER} (C) 2001 S. Karger AG, Basel

Fax + 41613061234 E-Mail karger@karger.ch www. karger.com
Accessible online at: www. karger.com/journals/uin 